\title{
A Few Parting Words
}

This is my last issue as editor of Nordicom Review, now in its $36^{\text {th }}$ year. The premiere issue appeared back in Spring 1981, springing out of a Nordic research newsletter launched the year before. The birth of the Nordicom Review marked the start of a new era for Nordicom; it was the first step toward becoming the Nordic knowledge center that Nordicom is today, with a presence in each of the Nordic countries as well as regional and international arenas.

In the Editor's column in that first issue I wrote:

It is our hope that the Nordicom Review will provide a channel for the Nordic mass communication research towards the world, and that it will make a valuable contribution to the exchange of information between mass communication researchers around the world.

In the early 1990s Nordicom Review became refereed and was counted among the leading quality journals in its field, with 2300 subscribers to the print version, 1600 of whom in more than 130 countries outside the Nordic region. Nordicom Review is also the most frequently downloaded publication on Nordicom's web site. In fact, today the Review reaches more readers via the web than subscribers to the print version.

I must say I find it gratifying to look back over the Review's history - it has formed the basis of a good part of Nordicom's other work, as well. And I am truly grateful for all the opportunities for contacts and collaboration between the Nordic region and the rest of the world that the journal has given us. They would not have been possible without it.

Therefore, I want to take this opportunity to thank you, all of our readers around the world, who have been so important to media researchers in our five Nordic countries.

And thanks also to the many Nordic researchers who have contributed to the journal these many years. The region's media and communication researchers are the core of Nordicom's work. Without them there would be no Nordicom Review - nor, for that matter, would Nordicom itself exist.

For me, personally, it has been a great privilege and pleasure to work in this research community - nationally, regionally and internationally.

This may be 'my' final issue of Nordicom Review, and I have left my position at Nordicom. But, I have not left media research. A couple of months 
ago I assumed the UNESCO Chair in Freedom of Expression, Media Development and Global Policy at the University of Gothenburg. The move means a return to the sector of the field that was the focus in my own research work.

It is my hope that some of my coming work may take place in collaboration with Nordicom, so if you have ideas that might be carried forward in this framework, please do get in touch.

In other words, this is not so much 'Farewell' as, hopefully, 'Au revoir'.

Once again, my heartfelt thanks for all the fruitful collaboration and many interesting conversations we have had through the years.

Göteborg in May 2015

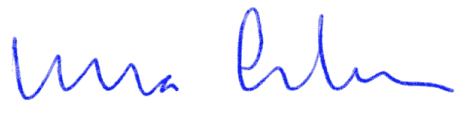

